\title{
Films based on bacteriorhodopsin in sol-gel matrices
}

\author{
S.O. Korposh ${ }^{\mathrm{a}, \mathrm{b}}$, M.Y. Sichka ${ }^{\mathrm{b}}$, I.I. Trikur ${ }^{\mathrm{b}}$, Y.P. Sharkan ${ }^{\mathrm{a}, \mathrm{b}}$, D.H. Yang ${ }^{\mathrm{c}}$, S.W. Lee ${ }^{\mathrm{c}}$, J.J. Ramsden ${ }^{\mathrm{a}, \mathrm{d}}$ \\ ${ }^{a}$ Cranfield University at Kitakyushu, KSRP, 2-5-4F Hibikino, Wakamatsu-ku, \\ Kitakyushu 808-0135, Japan; \\ ${ }^{\mathrm{b}}$ Institute of Solid-State Physics \& Chemistry, Uzhgorod National University \\ Voloshina St 54, Uzhgorod 88000, Ukraine; \\ 'Graduate School of Environmental Engineering, University of Kitakyushu, 1-1 Hibikino, \\ Kitakyushu 808-0135, Japan; \\ ${ }^{\mathrm{d}}$ Department of Advanced Materials, Cranfield University, MK43 0AL, UK
}

\begin{abstract}
The bacteriorhodopsin film in gelatin matrixes which are used as sensitive elements of integrated optic and fibre-optic sensors of various vapor and gases components will not be able to carry out the chemical control of aqueous solutions. In the given paper the results of technological development of obtaining the bacteriorhodopsin (bR) films in a sol-gel matrix are represented. The films are obtained in a broad thickness range (from 0.5 to 20 microns) with various bR concentrations and photosensitize additives. The optimal technological conditions of obtaining of uniform films with given optical parameters are defined. The surface morphology and cross section of the obtained films was studied using an AFM and SEM. The films have a reasonable surface roughness $(\sim 100 \mathrm{~nm})$ and a uniform distribution of the purple membrane fragments in the nanostructured sol-gel glass matrix along the films surface and thickness. The transmission spectrums have the characteristic for bR the absorption band, the value of which depends on bR concentration and technological features of the films deposition. The investigated photosensitive properties of the obtained films and influence on them of chemical components of aqueous solutions, allow recommending the thin bR films in sol-gel matrixes for creation of planar waveguides in the role of components of the chemical sensors of liquid solutions.
\end{abstract}

Keywords: Integrated-optic components, bacteriorhodopsin, sol-gel matrices

\section{INTRODUCTION}

In the past few years several biological molecules have been explored for their use in electronics and photonics applications. Bacteriorhodopsin (bR) ${ }^{1}$ has received the most attention because of its outstanding optical properties and excellent stability against chemical, thermal and photochemical degradation. bR is a retinal-protein complex; the absorption of a light quantum by the retinal leads to reversible colour changes from purple to yellow due to protein conformational changes, the molecule finally returning to the ground state. In other words, a cycle of reactions is initiated by light, during which the bR molecule passes from one intermediate state to another, the process being characterized by displacements of the optical absorption bands ${ }^{2}$. Figure 1 shows a simplified model of the bR photocycle ${ }^{2}$.

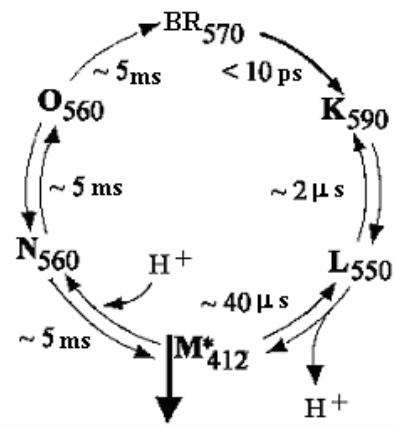

Figure 1: Photocycle of bR. Direct and back reactions, lifetime parameters of the photocycle intermediates, and the stages of protonation and deprotonation of the Schiff base are given.

Integrated Optics: Theory and Applications, edited by Tadeusz Pustelny, Paul V. Lambeck, Christophe Gorecki, Proc. of SPIE Vol. 5956, 595616, (2005) · 0277-786X/05/\$15 - doi: 10.1117/12.622631 
The influence of the external media on bR leads to reversible changes of his optical characteristics, which allow the creation of sensitive elements for optical sensor systems on this basis. For practical sensing applications, one can monitor the spectral and kinetic parameters of films made from bR incorporated into a matrix. Consideration of the question of external influences (e.g. due to the presence of ambient chemical substances) on the bR photochromic processes is of prime importance. By changing external conditions (temperature, hydrostatic pressure, electrical field intensity etc.) one can influence the photoinduced processes of the light-sensitive retinal-protein complex ${ }^{3,4}$. The chemical environment of bR also influences the photocycle parameters ${ }^{5}$. For example, humidity ${ }^{6,7}$, solutions of local anaesthetics ${ }^{8}$, organic vapours $^{9}$, ammonium ions and amines ${ }^{10,11}$, and ammonia ${ }^{12}$ all have demonstrable effects on the spectral and kinetic parameters. The effect of $\mathrm{pH}$ has also been studied ${ }^{13}$.

Inclusion of halogen-, nitrogen-, and sulphur-containing substances (called chemical additives) in various combinations into the film is a way to permanently modify the photosensitive and temporal characteristics of the photocycle over a wide range $\mathrm{e}^{7,8,14}$, with the possibility of enhancing the chemical sensitivity and selectivity of the films.

Polymer matrices, due to their simple and well-proven technology, are widely-used for the creation of films based on bR. They practically do not change the optical parameters and allow the preparion of bR in the form of thin films, which is convenient for practical applications.

Use of polymer matrices allows the creation of the sensitive elements based on bR for optical vapour sensors ${ }^{12}$. The drawback of the polymer matrix is its solubility, which makes it impossible to use it for the monitoring of aqueous media. Encapsulation of bR into a transparent, water insoluble matrix may solve this disadvantage, provided a bR-compatible material of adequate optical quality can be found.

The sol-gel process is a convenient and versatile method of preparing transparent optical and water insoluble matrices at moderate temperatures ${ }^{15}$. Ambient processing conditions enable one to create composite optical materials with numerous organic, organometallic and biological molecules embedded within a porous matrix of sol-gel glass ${ }^{16}$. Most sol-gel techniques use water and low molecular weight alkoxides such as tetraethoxysilane (TEOS) and tetramethoxysilane (TMOS) as sol-gel precursors ${ }^{17}$.

Hydrolysis and condensation of tetra-alkoxysilanes during the sol-gel process help to form a solid silicate around the sensing molecule, which is dissolved in the liquid phase ${ }^{16}$.

bR retains its optical properties when entrapped in silicate glass by the sol-gel process ${ }^{18,19}$, and could therefore be used for the envisaged biosensor application ${ }^{10}$. The preparation of dry films based on bR of high optical quality will considerably enhance the area of $b R$ applications as sensitive elements of integrated optic and fibre-optic sensors. Here we present the results from the technological development of preparing bacteriorhodopsin (bR) films in a sol-gel matrix. The result demonstrated that in water solutions the films based on bR in a sol-gel matrix retained their photoactivity.

\section{MATERIALS AND METHODS}

\subsection{Sample preparation}

Bacteriorhodopsin was extracted as purple membrane fragments (pmf) from Halobacterium salinarum, strain S9, cultured in our laboratory, according to standard procedures ${ }^{1,14}$. Tetraethoxysilane (TEOS) (Fluka Company, Switzerland) were used as precursors for the sol-gel glass. The sol-gel glass was prepared with slightly modified methods described earlier ${ }^{18}$. TEOS $(7 \mathrm{ml}), 3.0 \mathrm{ml}$ of distilled water and $0.1 \mathrm{ml}$ of $0.04 \mathrm{M} \mathrm{HC1}$ were mixed together and sonicated for $20 \mathrm{~min}$. The resulting product was diluted with an equal volume of distilled water. The resulting mixture $(0.5 \mathrm{ml})$ was mixed with $0.25 \mathrm{ml}$ sodium borate buffer solution $(\mathrm{pH} 9)$ and $(0.1 \mathrm{ml}, 0.2 \mathrm{ml}) \mathrm{bR}$ solution $(14 \mathrm{mg} / \mathrm{ml})$ to create a filmforming solution with different bR concentrations.

Triethanolamine (TEA) (Sigma) and dodecyltrimethylammonium bromide (DTMAB) (Sigma) were chosen as sensitizing additives. The concentration of chemical additives was in the range of 0.01-0.4 M. For the preparation of chemically modified films, bR solution was mixed with TEA and DTMAB, before mixing with the sol mixture, and afterwards $0.02 \mathrm{ml}$ of the bR-chemical additives mixture was added to $0.12 \mathrm{ml}$ of the sol mixture.

The film-forming mixture $(0.1 \mathrm{ml})$ was deposited onto $5 \mathrm{~cm}^{2}$ glass substrates for the creation of thick $(20 \mu \mathrm{m})$ pure solgel films and films of bR in the sol-gel matrix. The films were kept in the refrigerator at $4{ }^{\circ} \mathrm{C}$ for 24 hours. Surface measurements and cross section morphology were carried out using AFM and SEM.

The thin $(<1 \mu \mathrm{m})$ films were prepared by spin-coating methods, by deposition of a drop, with a volume of about $5 \mu \mathrm{l}$, of the film-forming mixture onto a rotating $(2500 \mathrm{rpm})$ glass substrate. 


\subsection{Film characterization}

Surface morphology of the films based on bR in the sol-gel matrix was studied with the help of a Jeol JSPM 5210 atomic force microscope. Films were deposited onto $5 \mathrm{~mm}^{2}$ glass substrates. Measurement was done in non-contact mode.

The morphology of the surface and cross-sections of the bR-based films was studied using a Hitachi S-5200 field emission scanning electron microscope (FE-SEM) at the Instrumentation Center, the University of Kitakyushu. Before measurements the films were vacuum dried for 6 hours in order to remove all water from the samples.

The spectral static or temporal characteristics were measured at room temperature using an HR2000 Ocean Optics fibreoptic spectrophotometer and a double beam Jasco V-550 UV-vis spectrophotometer.

For the measurements of photoinduced absorption changes an Ocean Optics LS-450 Blue LED Pulsed Light Source with the LED-518 $(\lambda=518 \mathrm{~nm})$ was used for photo excitation of the bR photocycle. The light was transported by means of a single $1000 \mu \mathrm{m}$ optical fiber (Ocean Optics, QP1000-2-UV-VIS) to the film fixed in the spectrophotometer chamber. The measurement was done at the wavelength 410 and $570 \mathrm{~nm}$, which correspond to the absorption maxima of the main intermediate $\mathrm{M}_{410}$ of the bR photocycle and the ground state $\mathrm{bR}_{570}$. The optical power density of the actinic light was unites of $\mathrm{mW} / \mathrm{cm}^{2}$. For the differential spectra, the spectrum of the illuminated sample was measured 5 min after the actinic light started.

The photoinduced absorption changes were calculated as the normalized ratio of the maximum absorbance of the unbleached sample $\left(\mathrm{A}_{570 \max }-\mathrm{A}_{570 \operatorname{maxbleached}}\right) / \mathrm{A}_{570 \max }$.

Also measured was the half-time of the M state decay $\left(\tau_{1 / 2}\right)$, i.e. the time to achieve a change of absorbance of 0.5 after turning off the actinic illumination.

\section{RESULTS AND DISCUSSION}

\subsection{Sample morphology and structural characterization}

The surface of the TEOS film prepared by layering and drying is uniform and possesses a low roughness (Fig. 2). Incorporation of bR into the TEOS sol-gel matrix considerably increases the film surface roughness (Fig. 3). We assume that it is due to aggregation of the fragments of purple membranes and formation of big bR conglomerates. The deposition of sol-gel films onto the glass substrate by spin-coating can improve the films, optical quality.

The studies of film cross sections showed that films have a uniform nanostructure characterized by purple membrane fragments with an average diameter of $0.5 \mu \mathrm{m}$ and width $5 \mathrm{~nm}$ evenly stacked practically parallel to the substrate surface in the matrix (Fig. 4 and 5). The films have strongly developed micro- and mesoporosity. This suggests that during the adsorption of vapours not only surface but the entire film volume is involved, thereby considerably enhancing the efficiency of sensor operation. The thickness of films deposited by layering and drying was 10-20 $\mu \mathrm{m}$ (Fig. 4 and 5), and of films deposited by spin-coating $<1 \mu \mathrm{m}$ (not shown).

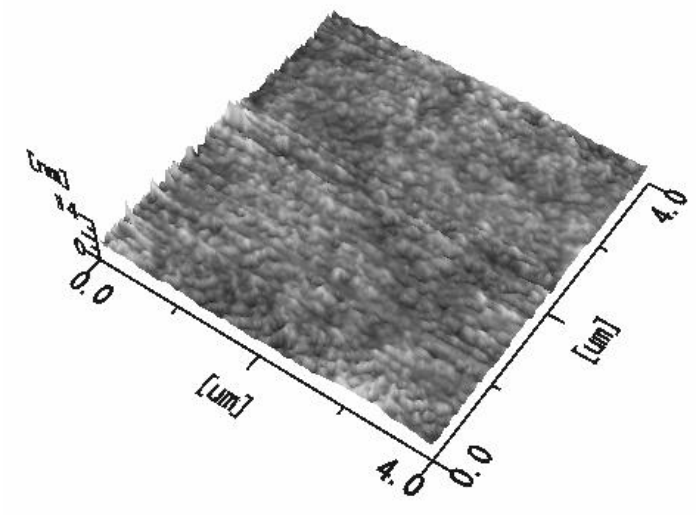

Figure 2: Surface morphology of a TEOS sol-gel matrix, prepared by layering and drying.

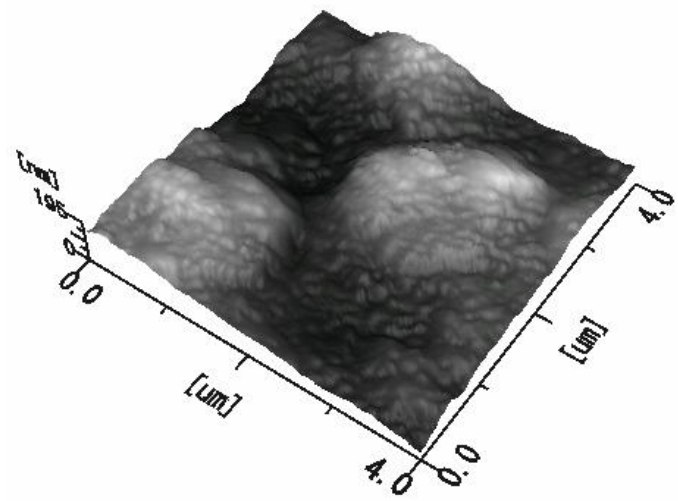

Figure 3: Surface morphology of films based on bacteriorhodopsin in a TEOS sol-gel matrix, prepared by layering and drying. 


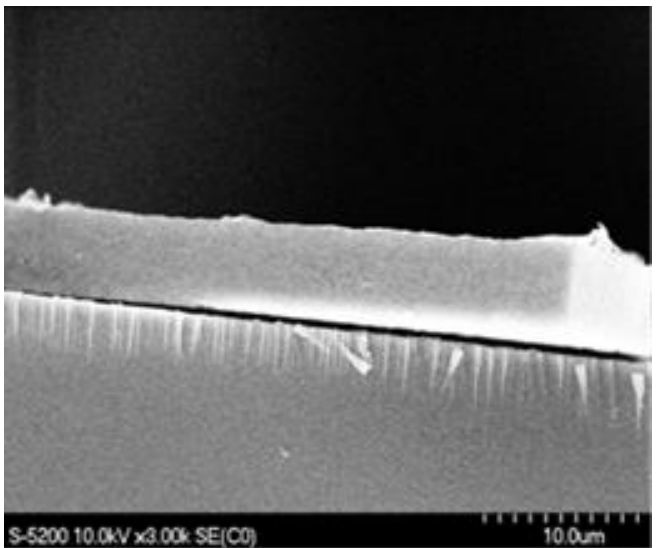

(a)

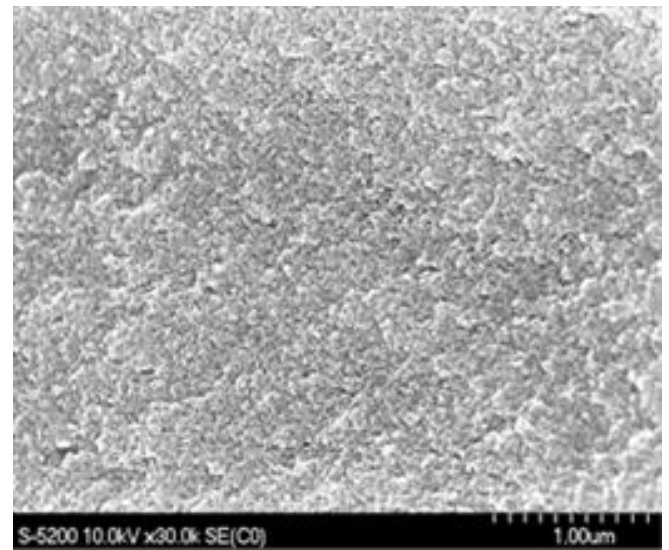

(b)

Figure 4: Cross section of a TEOS sol-gel matrix, prepared by layering and drying; (a) scale 10 $\mu \mathrm{m}$; (b) scale $1 \mu \mathrm{m}$.

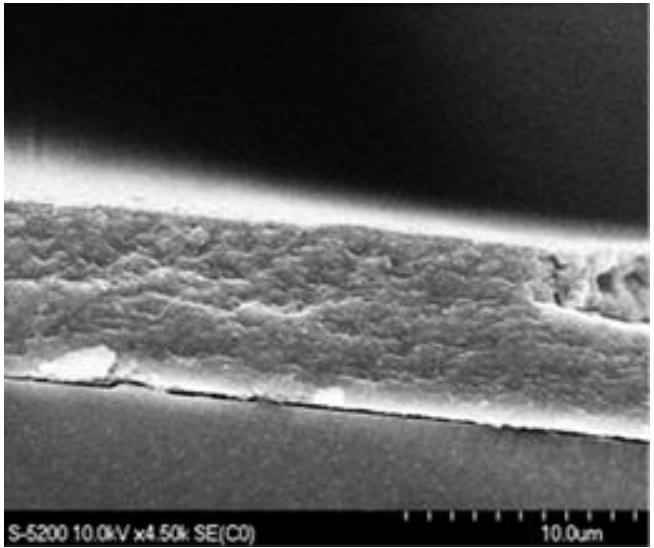

(a)

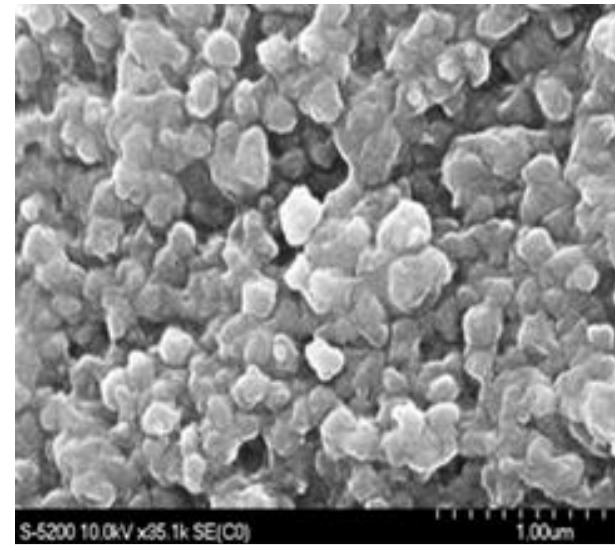

(b)

Figure 5: Cross section of films based on bR in a TEOS sol-gel matrix, prepared by layering and drying; (a) scale $10 \mu \mathrm{m}$; (b) scale 1 $\mu \mathrm{m}$.

\subsection{Spectral measurements of bR film in the sol-gel matrix}

bR has a characteristic absorption maximum at $570 \mathrm{~nm}$ due to the retinal chromophore, which is covalently bound to the apoprotein of bR through a protonated Schiff base linkage. The optical absorption spectra of films based on bR in a solgel matrix with bR different concentrations is shown in Figure 6. The characteristic absorption maxima proved that in the dry sol-gel film bR retains its optical properties and structure and is not denaturated.

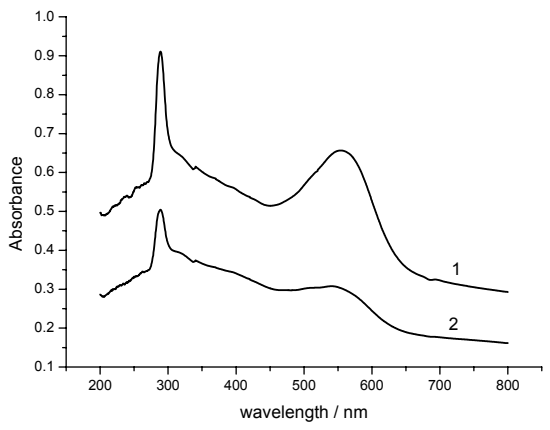

Figure 6: Absorption spectra of films based on bR in sol-gel matrix. 1, mass ratio bR : TEOS $=5,5 \%: 94,5 \% ; 2$, bR : TEOS $=$ $2,25 \%: 97,75 \%$. 
Preparing films with the higher bR concentration increases the film sensitivity and at the same time the optical quality is still good and light scattering is relatively low.

\subsection{Photoinduced changes of bR optical properties}

Absorption of light quanta in the visible spectral range initiated the photochemical cycle in $b R$, followed by the photochromic shift with absorption decreasing at $570 \mathrm{~nm}$ and a new absorption maximum appearing at $410 \mathrm{~nm}$. The new maximum at $410 \mathrm{~nm}$ indicates the formation of the photointermediate $\mathrm{M}_{410}$ and proved that bR retains its photoactivity in the dry sol-gel film (Fig. 7).

The main parameters of the bR photocycle are the formation kinetics and the decay half-time of the $\mathrm{M}_{410}$ intermediate. The photoinduced absorption changes of films based on bR in sol-gel matrix, monitored at $410 \mathrm{~nm}$ and $570 \mathrm{~nm}$, which correspond to the absorption maxima of the $\mathrm{M}$ intermediate and the bR ground state, are shown in Figure 8. Inclusion of the chemical additives into the film composition increases the lifetime of the $\mathrm{M}$ intermediate and of the corresponding photoinduced absorption changes (Fig. 9). The main optical characteristics for the films based on bR in sol-gel matrix with different chemical additives are summarized in Table 1. The highest photoinduced absorption change and longest lifetime is seen in films with added TEA.

Table 1. Optical characteristics for the films based on $\mathrm{bR}$ in sol-gel matrix with chemical additives.

\begin{tabular}{|c|c|c|c|}
\hline Film composition & $\lambda / \mathrm{nm}$ & $\begin{array}{c}\Delta \mathrm{A} \lambda_{\max } / \mathrm{A} \lambda_{\max } \\
(\%)\end{array}$ & $\begin{array}{c}\tau_{1 / 2} / \mathrm{s} \\
( \pm 0.1)\end{array}$ \\
\hline bR+TEOS & 570 & 2.9 & 12 \\
\hline bR+TEOS+TEA & 410 & 1.9 & 21 \\
\hline bR+TEOS+TEA+ DTMAB & 570 & 4.6 & 13 \\
\hline
\end{tabular}

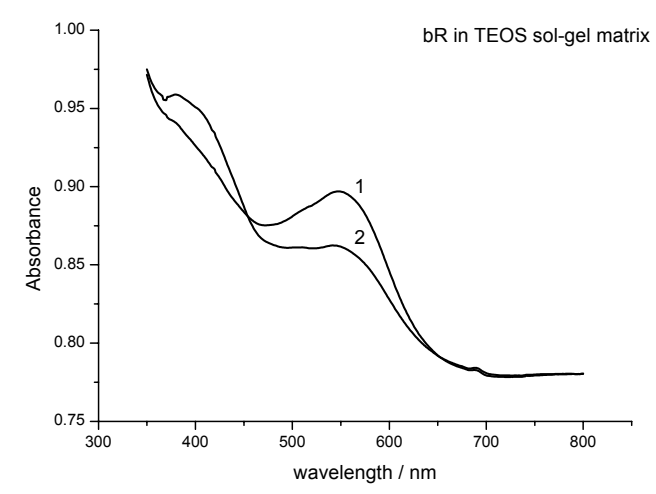

Figure 7: Absorption spectra of films based on bR in a sol-gel matrix; 1 - bR in the ground state; 2 - in the presence of actinic light.

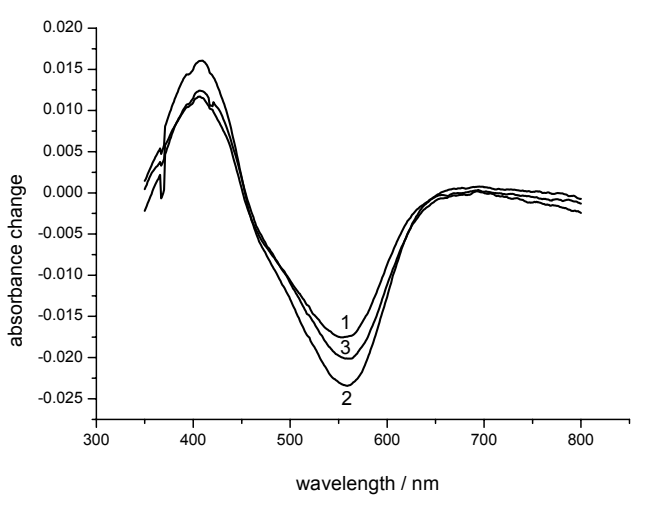

Figure 9: Differential absorbance spectra (light minus dark) of bR in sol-gel matrix with different chemical additives; 1- bR+TEOS; 2 - bR+TEOS+TEA; 3$\mathrm{bR}+\mathrm{TEOS}+\mathrm{TEA}+\mathrm{DTMAB}$. 


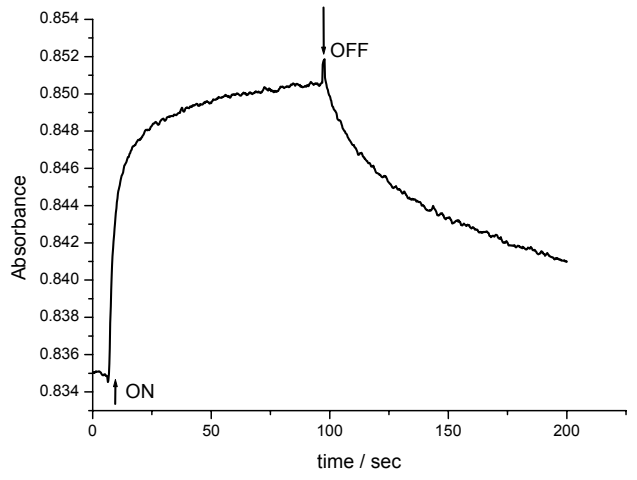

(a)

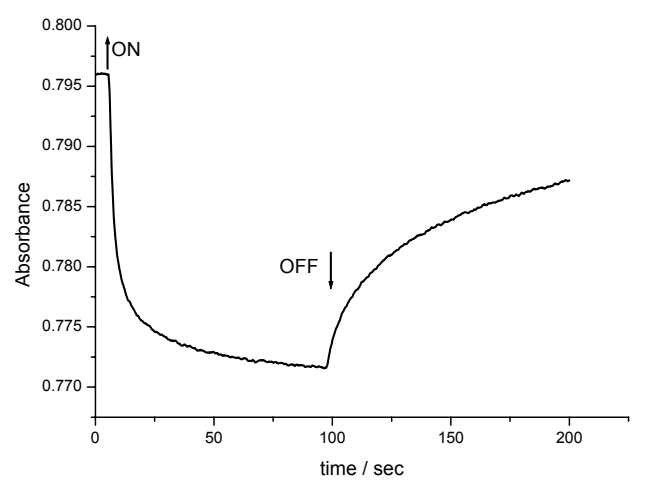

(б)

Figure 8: Time dependence of photoinduced absorbance change of bR in sol-gel matrix monitored at $410 \mathrm{~nm}$ and $570 \mathrm{~nm}$ during and after actinic illumination. (a) $410 \mathrm{~nm}$; (b) $570 \mathrm{~nm}$.

Water plays a very important role in the bR photocycle ${ }^{20,21}$. With decreasing relative humidity a blue shift in the absorbance maximum for the bR film along with a decrease of absorption is observed ${ }^{6}$. Different matrices possess different porosities and they will contain different amounts of water around the bR molecule, which will influence the properties of bR photocycle. In order to check the effect of the matrix materials on the photoinduced bR optical properties, the parameters of films based on $\mathrm{bR}$ in polymeric matrices and in a sol-gel glass matrix were compared. The differential absorption spectra of the films based on bR in different matrices is shown in Figure 10.

Comparing three different films types: bR in polyvinyl alcohol, in gelatin and in sol-gel glass, it is evident that the gelatin film contains the largest amount of available water and the polyvinyl alcohol film the least. In the polyvinyl alcohol water is strong bonded with the polymer chains (via numerous hydrogen bonds with the hydroxyl groups of the polyvinyl alcohol) and is not accessible to the bR chromophore ${ }^{21}$.

These results demonstrate the possibility to control and modify bR photocycle properties by choosing the matrix type.

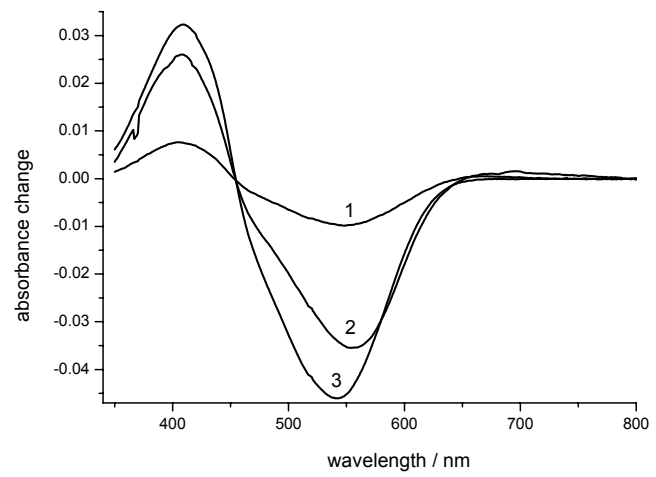

Figure 10: Differential absorbance spectra (light minus dark) of films based on bR in different matrices; 1, bR in gelatin; 2, bR in TEOS; 3, bR in polyvinyl alcohol.

\subsection{Performance of $b R$ film in liquid medium}

In order to check the performance of bR films in liquid solutions the optical characteristics of films based on bR in the sol-gel matrix were measured in films immersed into the water. Figure 11 depict the photoinduced absorption changes of bR films in air and in water. The film based on bR in a sol-gel glass was not dissolved and retained its photoactivity in the liquid medium. Absorption changes of the film immersed into the water can be due to decreasing of the light scattering in the bR film in sol-gel glass. Penetration of water into pores displaces the air in the pore, and decreases the mismatch between refractive indexes of sol-gel matrix and its pores, resulting on decreasing of light scattering. 


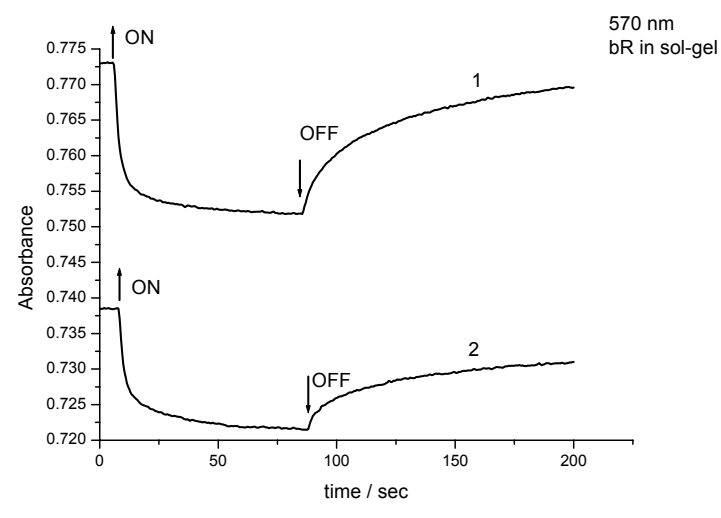

(a)

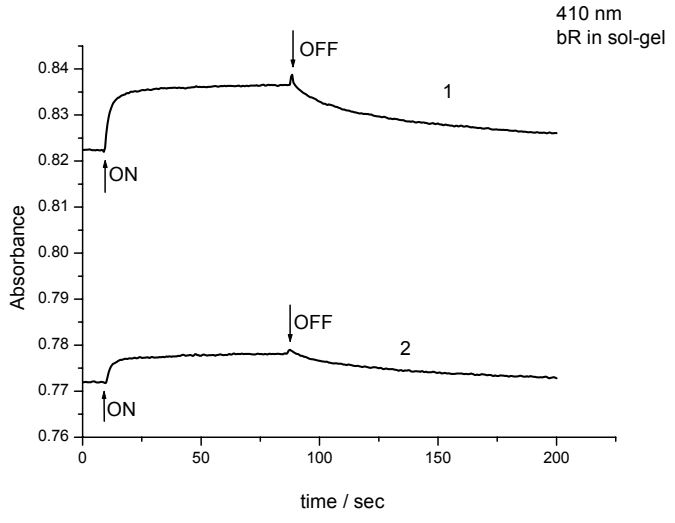

(b)

Figure 11: Time dependence of photoinduced absorbance change of bR in a sol-gel matrix monitored at $410 \mathrm{~nm}$ and $570 \mathrm{~nm}$ during and after actinic illumination, 1, in air; and 2, in a liquid medium (pure water). (a) $570 \mathrm{~nm}$; (b) $410 \mathrm{~nm}$.

The results obtained indicate possible applications of film structures based on $\mathrm{bR}$ in a sol-gel matrix as the sensitive elements of integrated optic and fibre-optic sensors. Films based on bR in sol-gel glass are not dissolved and retain their photoactivity in the liquid medium, which allow the use of these structures as sensitive elements of sensors in a system for monitoring the chemical composition of liquid aqueous solutions. A further technological improvement is necessary in order to obtain bR films in the sol-gel glass with the proper optical quality.

\section{REFERENCES}

1. Oesterhelt D., Stoeckenius W. Functions of a new photoreceptor membrane. Proc. Natl. Acad. Sci. USA, 1973, Vol.70, pp. 2853-2857.

2. R.H. Lozier, R.A. Bogomolni and W. Stoeckenius, Bacteriorhodopsin: a light-driven proton pump in Halobacterium halobium. Biophys. J., 1975, Vol.15, pp. 955-962.

3. Subramaniam., Gerstein M., Oesterhelt D., Henderson R. Electron diffraction analysis of structural changes in the photocycle of bacteriorhodopsin. The EMBO Journal, 1993, Vol.12, pp.1-8

4. G. Váró and J.K. Lanyi, Effects of hydrostatic pressure on the kinetics reveal a volume increase during the bacteriorhodopsin photocycle. Biochemistry, 1995, Vol. 34, pp. 12161-12169.

5. A. Dér and J.J. Ramsden, Evidence for loosening of a protein mechanism. Naturwissenschaften, 1998, Vol. 85, pp. 353-355.

6. T.V. Dyukova and E.P. Lukashev, Dehydration effects on D96N bacteriorhodopsin films. Thin solid Films, 1996, Vol. 283, pp. 1-4.

7. Z. Batori-Tartsi and K. Ludmann, Chemically modified bacteriorhodopsin based photosensitive material for optoelectronic application. Bioelectronic Applications of Photochromic Pigments, A. Dér and L. Keszthelyi (eds). Amsterdam: IOS Press (2001), pp. 137-148.

8. A. Shibata, A. Yorimitsu, H. Ikema, K. Minami, S. Ueno, E. Muneyuki, and T. Higuti, Photocurrent of purple membrane adsorbed onto a thin polymer film: action characteristics of the local anesthetics. Colloids Surfaces B, 2002, Vol. 23, pp. 375-382.

9. E. Maccioni, G. Radicchi, V. Erokhin, S. Paddeu, P. Facci and C. Nicoloni, Bacteriorhodopsin thin film as a sensitive layer for an anaesthetic sensor. Thin Solid Films, 1996, Vol. 284-285, pp. 898-900.

10. P.C. Pandey, Sudha Singh, Bipin Upadhyay, Howard H. Weetall and Peter K. Chen, Reversal in the kinetics of the M state decay of D96N bacteriorhodopsin: probing of enzyme catalyzed reactions. Sensors and Actuators B, 1996, Vol. 35-36, pp. 470-474.

11. P.C. Pandey, B.C. Upadhyay, C.M.D. Pandey and H.C. Pathak, Dependence of M, N and O states decay kinetics of D96N bacteriorhodopsin on amine and amino compounds and its application in chemical sensing. Sensors and Actuators B, 1998, Vol. 46, pp. 80-86.

12. J.P. Sharkany, S.O. Korposh, Z.I. Batori-Tarci, I.I. Trikur, J.J. Ramsden, Bacteriorhodopsin-based biochromic films for chemical sensors. Sens. Actuators B, 2005, Vol. 107, pp. 77-81. 
13. L. Zimanyi, Y. Cao, R. Needleman, M. Ottolenghi and J.K. Lanyi, Pathway of Proton Uptake in the Bacteriorhodopsin Photocycle. Biochemistry, 1993, Vol. 32, pp. 7669-7678.

14. A. Kikineshy, Z. Bathori-Tarczy and Y. Sharkany, In: W.K. Jones, G. Harsanyi (eds) Multichip Modules with Integrated Sensors. NATO ASI Series 3, High Technology. Dordrecht: Kluwer, 1996, pp. 181-184.

15. C.L. Dorothy, D. Bruce, Jeffrey, I.Z., 1996. Room temperature luminescence of silicate sol-gel materials containing trisodium Tris(dipicolinato) neodymate (III). Inorg. Chem. 35, 2152-2154.

16. R. Gupta, S. Mozumdar, N.K. Chaughury, Fluroscence spectroskopic studies to characterize the internal environment of tetraethyl-orthosilicate derived sol-gel bulk and thin films with aging. Biosensors and Bioelectronics, 2005, Vol. 20, pp. 1358-1365.

17. O. Lev, M. Tsionsky, L. Rabinovich, V. Glezer, S. Sampath, I. Pankratov, J. Gun, Organically modified sol-gel sensors. Anal. Chem., 1995, Vol. 67, pp. 22A-30A.

18. H. Weetall, Retention of bacteriorhodopsin activity in dried sol-gel glass. Biosensors \& Bioelectronics, 1996, Vol. 11, pp. 325333.

19. W.U. Shuguang, L. M. Ellerby, J. S. Cohan, B. Dunn, M. A. El-Sayed, J. Selverstone Valentine, and J. I. Zink, Bacteriorhodopsin Encapsulated in Transparent Sol-Gel Glass: A New Biomaterial. Chem. Mater., 1993, Vol. 5, pp. 115120.

20. P. Hildebrandt and M. Stockburger, Role of Water in Bacteriorhodopsin's Chromophore: Resonance Raman Study. Biochemistry, 1984, Vol. 23, pp. 5539-5548.

21. N.N. Vsevolodov, Biomolecular Electronics, 1998, Boston: Birkhäuser. 